\title{
artigo
}

Gomes, J.D.P.; Brandão, M.G.S.A.; Freitas da Silva, N.M.; Mendes, N.U.; Carvalho, C.M.L.; Grimaldi, M.R.M.;

Percepções sobre cultura, saúde e religiosidade em museu senzala

\section{Percepções sobre cultura, saúde e religiosidade em museu senzala}

\author{
Perceptions on culture, health and religiosity in senzala museum \\ Percepciones sobre cultura, salud y religiosidad en el museo de senzala
}

\begin{abstract}
RESUMO
Objetivo: relatar a experiência de visita a um Museu Senzala, conduzida por mestrandos em enfermagem, como parte da disciplina Teoria do Conhecimento e Enfermagem, do Mestrado Acadêmico da Universidade da Integração Internacional da Lusofonia Afro-Brasileira. Método: estudo qualitativo, descritivo, do tipo relato de experiência, sobre a realização de seminário extramuros da universidade em abril de 2019. Os participantes foram 18 discentes e duas docentes. Os dados foram coletados por meio do olhar qualitativo dos autores através de diário de campo, a fim de abordar aspectos culturais, religiosos e saúde presentes no referido Museu. Resultados: o seminário proporcionou conhecimento aprofundados sobre a história do Museu e propor uma narrativa visual crítica, com levantamento de questionamentos sobre a história local, cultural, aspectos religiosos e saúde dos povos africanos. Conclusão: é relevante que patrimônios históricos possam ser utilizados por discentes e docentes como ambiente de aprendizagem e resgate de fatos e marcos reais da história brasileira.
\end{abstract}

DESCRITORES: Educação; Saúde; Enfermagem; Religião; Cultura.

\section{ABSTRACT}

Objective: to report the experience of visiting a Senzala Museum, conducted by master's students in nursing, as part of the Theory of Nursing Knowledge course, provided by the Academic Master's Program at the University for International Integration of the Afro-Brazilian Lusophony. Method: Method: a qualitative, descriptive, experience report type study on the realization of an extramural seminar at the university in April 2019. Participants were 18 students and two teachers. The data were collected through the qualitative view of the authors through a field diary, in order to address cultural, religious and health aspects present in the said Museum. Results: the seminar provided in-depth knowledge about the history of the Museum and proposed a critical visual narrative, raising questions about the local, cultural, religious and health aspects of African peoples. Conclusion: it is relevant that historical heritage can be used by students and teachers as an environment for learning and recovering facts and real milestones of the Brazilian history.

DESCRIPTORS: Education; Health; Nursing; Religion; Culture.

\section{RESUMEN}

RESUMEN

Objetivo: informar sobre la experiencia de la visita a un Museo Senzala, efectuada por estudiantes de maestría en enfermería, como parte de la asignatura Teoría del Conocimiento y Enfermería, del Máster Académico de la Universidad de Integración Internacional de la Lusofonía Afrobrasileña. Método: estudio cualitativo, descriptivo, tipo relato de experiencia sobre la realización de un seminario extramuros en la universidad en abril de 2019. Los participantes fueron 18 estudiantes y dos docentes. Los datos fueron recolectados a través de la mirada cualitativa de los autores a través de un diario de campo, con el fin de abordar aspectos culturales, religiosos y de salud presentes en dicho Museo. Resultados: el seminario proporcionó un conocimiento profundo sobre la historia del Museo y propuso una narrativa visual crítica, planteando interrogantes sobre los aspectos locales, culturales, religiosos y de salud de los pueblos africanos.Conclusión: es relevante que los patrimonios históricos puedan ser utilizados por alumnos y maestros como entornos de aprendizaje y rescate de hechos e hitos reales de la historia brasileña.

DESCRIPTORES: Educación; Salud; Enfermería; Religión; Cultura.

RECEBIDO EM: 26/01/2021 APROVADO EM: 09/02/2021

\section{Júlia Diana Pereira Gomes}

Enfermeira, Mestranda em Enfermagem pela Universidade da Integração Internacional da Lusofonia Afro-Brasileira (UNILAB).

ORCID: 0000-0003-4846-7147 
Maria Girlane Sousa Albuquerque Brandão

Enfermeira, Doutoranda em Enfermagem Fundamental pela Universidade de São Paulo (USP).

ORCID: 0000-0002-9925-4750

Nargila Maia Freitas da Silva

Enfermeira, Mestranda em Enfermagem pela Universidade da Integração Internacional da Lusofonia Afro-Brasileira (UNILAB). ORCID: 0000-0003-1036-8944

Nicásio Urinque Mendes

Enfermeiro, Mestrando em Enfermagem pela Universidade da Integração Internacional da Lusofonia Afro-Brasileira (UNILAB). ORCID: 0000-0002-7636-5941

\section{Carolina Maria de Lima Carvalho}

Doutora, Enfermeira. Professora do Programa de Pós-Graduação em Enfermagem da Universidade da Integração Internacional da Lusofonia Afro-Brasileira (UNILAB).

ORCID: 0000-0002-5173-5360

\section{Monaliza Ribeiro Mariano Grimaldi}

Doutora, Enfermeira. Professora do Programa de Pós-Graduação em Enfermagem da Universidade da Integração Internacional da Lusofonia Afro-Brasileira (UNILAB).

ORCID: 0000-0002-8718-4783

\section{INTRODUÇÃO}

A $s$ estratégias de ensino aprendizagem em cursos de mestrado acadêmico devem ir além da metodologia tradicional e utilizar metodologias ativas, com ênfase em situações problema, ensino com pesquisa, estudos de casos clínicos, atuação e aprendizagem em grupo, aulas dialogadas e participativas, aprendizagem em equipe, dinâmicas de tempestade cerebral com tecnologias de ensino e seminários em campo. ${ }^{1,2}$

Metodologias ativas possibilitam transformações no ensino superior, de forma a motivar os mestrandos a sair do método tradicional de aprendizagem e colabore com o desenvolvimento de um olhar crítico que auxilie no exercício de sua profissão.

Museus são locais que possuem patrimônio material e imaterial; e portanto; possuem características peculiares que podem ser utilizadas como metodologia de aprendizagem, pois constituem uma das formas de narrativa e aprendizagem da história cultural e podem incentivar os discentes a considerar o contexto de seus preconceitos em vez de absorver passivamente representações convencionais. 3,4

Estes espaços possibilitam que muitos fatos e vestígios de épocas remotas, por meio da sua conservação, possam ser vivenciados e apreciados pela sociedade e pesquisadores, com permissividade para novas reflexões sobre fatos passados.

Tais locais devem ser objeto de estudo de estudantes e universitários, uma vez que os museus são considerados ambientes de epifanias, de produção de conhecimento, inserção social e econômica, sendo não apenas um lugar de conservação mas, também, de ressignificação do patrimônio. ${ }^{5}$

Desse modo, o destaque às múltiplas vivências e alternativas das populações negras ao longo da nossa história, por meio do patrimônio cultural e de exposições museológicas, contribui para a divulgação de um conhecimento atual, fruto de pesquisas acadêmicas recentes sobre o tema. ${ }^{6}$

O Museu Senzala Negro liberto localiza-se próximo à Universidade da Integração Internacional da Lusofonia Afro-Brasileira - UNILAB. A universidade foi fundada em 2009 e está voltada aos Países Africanos de Língua Oficial Portuguesa (PALOP).

O museu pode ser utilizado como campo de ensino, em face de seu contexto de criação, por meio da parceria com outros países africanos, como forma de desenvolver o crescimento econômico, político e social entre estudantes, e assim, formar cidadãos capazes de multiplicar aprendizado. ${ }^{7,8}$

Desse modo, o presente estudo tem como objetivo relatar a experiência de visita a Museu Senzala, conduzida por mestrandos em enfermagem, como parte da disciplina Teoria do Conhecimento e Enfermagem, do Mestrado Acadêmico da Universidade da Integração Internacional da Lusofonia Afro-Brasileira.

\section{MÉTODO}

Trata-se de estudo qualitativo, descritivo, do tipo relato de experiência, sobre realização de seminário extramuros da universidade, por discentes do Mestrado Acadêmico em Enfermagem da Universidade da Integração Internacional da Lusofonia Afro-Brasileira-UNILAB, como parte da disciplina Teoria do Conhecimento e Enfermagem, em abril de 2019.

O cenário do seminário extramuros foi o Museu Senzala Negro Liberto, patrimônio histórico no município de Redenção, Ceará, Brasil. O museu iniciou suas atividades no ano de 2003 e está aberto ao público até os dias atuais. Ocupa a sede de antiga fazenda que possuía regime escravista. À margem da rodovia, na Avenida Abolição, na entrada da cidade. Atualmente, o museu recebe visitas de conterrâneos, universitários, docentes e turistas.

A população-alvo foi representada por 20 discentes do mestrado em enfermagem da UNILAB da turma (2019-2020). Todos os discentes receberam o convite em sala de aula, presencialmente, e por meio virtual, 


\section{artigo}

Gomes, J.D.P.; Brandão, M.G.S.A.; Freitas da Silva, N.M.; Mendes, N.U.; Carvalho, C.M.L.; Grimaldi, M.R.M.;

Percepções sobre cultura, saúde e religiosidade em museu senzala

através do aplicativo de mensagens WhatsApp. O seminário contou com a participação de 18 discentes e duas doutoras em enfermagem, docentes do mestrado.

\section{Figura 1. Entrada do Museu Senzala Negro Liberto}

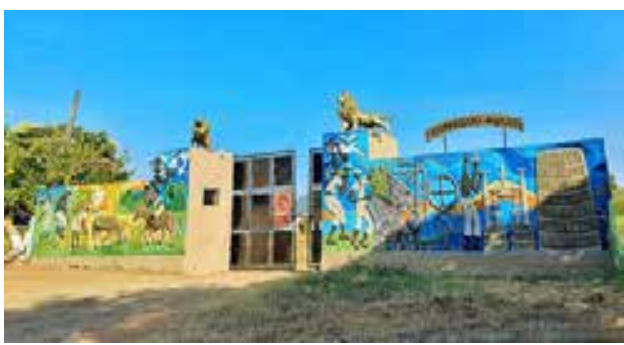

Fonte: https:/www.youtube.com/watch?v=UAsBOIY2mEO

\section{Figura 2. Casa Grande}

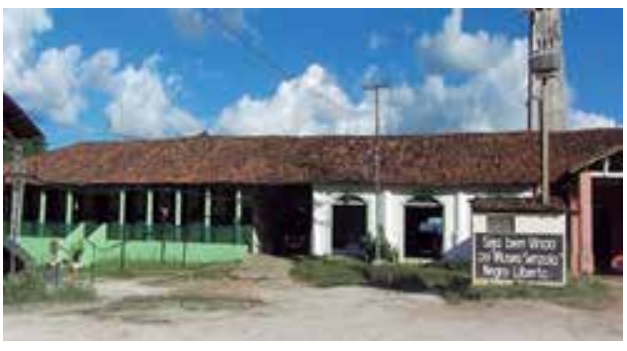

Fonte: https:/cearapraias.com.br/redencao-ecoturismo-com-lazer-e-cultura/

\section{Figura 3. Documento histórico da libertação}

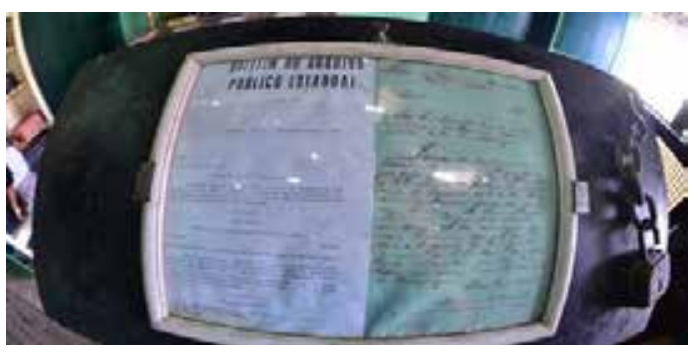

Fonte: http:/www.rodandopeloceara.com.br/2015/11/museu-senzala-negro-liberto-redencao.html

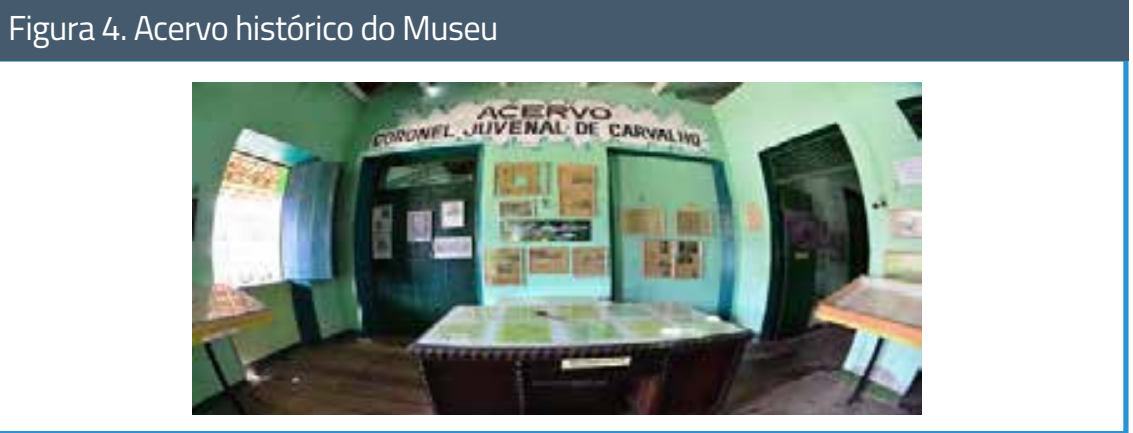

Fonte: http://www.rodandopeloceara.com.br/2015/11/museu-senzala-negro-liberto-redencao.html do museu, com explanação dos locais e constituintes da história para os convidados discentes e docentes da disciplina.

Em cada local da visita, foram abordados acontecimentos relacionados ao contexto histórico, o modo de vida dos escravos e de seus donos, formas de trabalho e costumes relacionados à espiritualidade.

Os quatro mestrandos responsáveis pela logística do seminário, realizaram diário de campo com anotações sobre todas as impressões e falas dos discentes e docentes durante o seminário. Ao final, se reuniram para analisarem todo o conteúdo produzido por meio dos diários de campo e unifica-lo em um produto final (artigo).

Assim, o estudo apresenta o olhar qualitativo dos autores, a fim de abordar aspectos culturais, religiosos e saúde presentes no referido Museu, com descrição dos aspectos de maior relevância, emergidos da vivência dos autores e participantes ao entrarem em contato com o local visitado, usando como demonstrativo do tema proposto para o seminário, ao qual tratava-se da caracterização do conhecimento religioso e enfermagem, acerca dos países constituintes da Comunidade dos Países de Língua Portuguesa (CPLP).

$\mathrm{O}$ estudo não necessitou de aprovação de Comitê de Ética e Pesquisa. Todas as produções científicas utilizadas na pesquisa foram devidamente citadas e referenciadas, em respeito aos direitos autorais.

\section{RESULTADOS E DISCUSSÃO}

A visita teve duração de quatro horas, que perpassou pelo engenho, casa grande, senzala, canavial e loja de produtos obtidos da cachaça. Por meio da visita guiada foi possível conhecer mais profundamente sobre a história do Museu e regime escravista da época e propor uma narrativa visual crítica, com levantamento de questionamentos sobre a história local.

Por meio dessa vivência foi possível identificar que experiências subjetivas dos participantes foram colocadas em confronto com exposições do museu e discutir, por exemplo, questões históricas, como a concessão, em 25 de março de 1883, de alforria a todos os negros cativos, cinco anos antes da Lei Áurea pela princesa Isabel. 
Os documentos locais da libertação presente no Museu foram analisados pelos participantes da visita guiada e discutida a real motivação da libertação pelos partici-

pantes: "Bondade?" ou "Interesse político-monetário?”.

Assim, percebe-se que os museus são locais que incitam o pensamento crítico-refle-

\section{Figura 5. Objeto de tortura (Vira-mundo)}

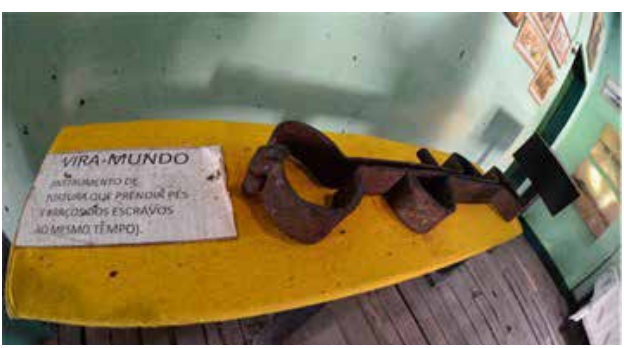

Fonte: http://www.rodandopeloceara.com.br/2015/11/museu-senzala-negro-liberto-redencao.html

\section{Figura 6. Objeto de tortura (Algemas/Gargalheira)}

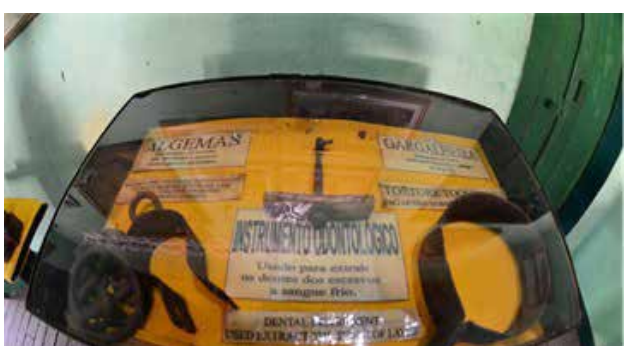

Fonte: http://www.rodandopeloceara.com.br/2015/11/museu-senzala-negro-liberto-redencao.html

\section{Figura 7. Senzala}

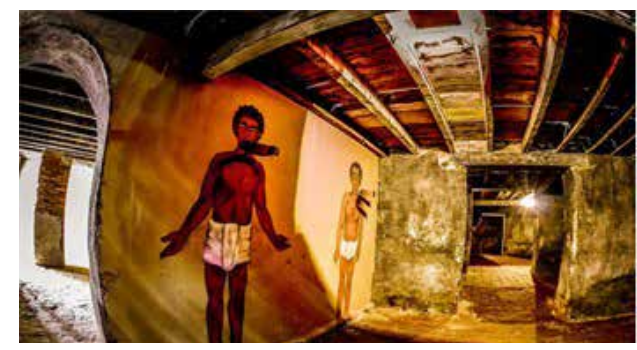

Fonte: http:/www.rodandopeloceara.com.br/2015/11/museu-senzala-negro-liberto-redencao.html

\section{Figura 8. Senzala}

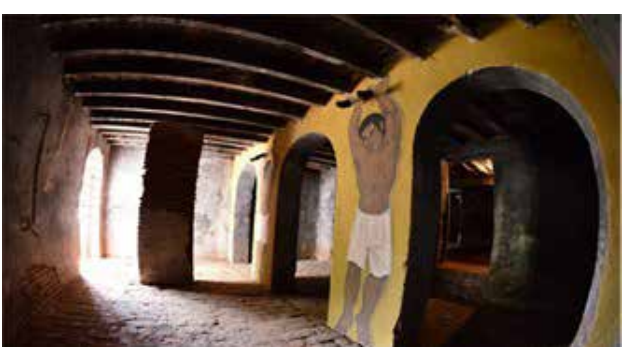

Fonte: http://www.rodandopeloceara.com.br/2015/11/museu-senzala-negro-liberto-redencao.html xivo dos que os visitam, fazendo-os levantar questionamentos sobre o passado e ter acesso por meio dos patrimônios materiais e imateriais a reflexões sobre a realidade vivenciada na época e sua conjuntura política.

Um museu é um espaço educativo um ambiente não formal que pode oportunizar narrativas pessoais, pois, além de ativar memórias, pode nos provocar à produção de subjetividades que interferem no jogo entre imaginação e entendimento. ${ }^{9} \mathrm{O}$ processo de formação do ser humano vai muito além do espaço universitário ou escolar. As aprendizagens podem ser conquistadas nas relações interpessoais e nas vivências concretas e significativas desenvolvidas não pelos cenários de educação formal/tradicional, mas também em outros ambientes. Portanto, é necessário extrapolar os muros da escola/universidade e possibilitar aos discentes múltiplas vivências. ${ }^{10}$

Muitos sentimentos foram provocados na visita à casa-grande, objetos patrimoniais do lar, artefatos de tortura, quadros e pinturas, despertaram novos sentidos na construção do saber. Muitos participantes tocavam objetos de tortura e apresentavam expressão facial de tristeza ao ver a forma que muitos artefatos eram utilizados, como fonte de martírio físico, como demonstrados nas figuras 5 e 6 .

Nesse ínterim, é possível identificar que a historicidade da condição humana requer que as práticas de poder e dominação sejam renovadas. Os chamados legados dos horrores passados: escravidão, colonialismo ou holocausto, só são possíveis por causa dessa renovação, que só ocorre no presente. Assim, mesmo em relação ao passado, são necessárias as lutas do presente para que o passado não se repita. ${ }^{11}$

A senzala do museu possui uma característica especial que a diferencia das outras no cenário brasileiro, pois está construída no subsolo e guarda memórias do século XVIII que retratam o momento vivido no país na época do binômio escravo e senhor de engenho. Foi possível perceber as condições precárias que os escravos vivenciavam naquele local escuro, sem luz, ventilação e com estrutura em forma de labirinto. $\mathrm{O}$ local não possui eletricidade, e por ficar no 
subsolo também não há ventilação, como demonstra as figuras 7 e 8 .

Alguns participantes desistiram de continuar a visita pelo interior da senzala por variados motivos: calor excessivo, pouca luminosidade e ventilação, sensação de aprisionamento pelo formato de labirinto e pela quantidade de morcegos, que podem chegar a mais de três mil em determinadas épocas do ano.

De acordo com esse cenário, ressalta-se que o infeliz legado da escravidão reaparece como trauma histórico a ser superado e serve de base aos pedidos de reparação. ${ }^{12} \mathrm{Tal}$ sentimento avigora a importância de momentos extra sala, que possibilitem experiências reais que despertem novas formas de pensar e agir.

Em uma das galerias da senzala que era destinada aos escravos para expressão de cultos a divindades, discutiu-se criticamente sobre entidades religiosas, conhecidas como orixás, em que foi possível compreender que os escravos africanos acreditavam que os espíritos Orixás eram seus ancestrais africanos que foram divinizados, e que, tais Orixás também representam suas entidades no processo saúde-doença. Contudo, ainda percebe-se uma noção equivocada das práticas culturais de origem africana, conhecida pejorativamente como macumba. ${ }^{13}$

Além da religiosidade Orixá, foram discutidas outras religiões de matriz africana, como o Candomblé e Umbanda. Desse modo, como o catolicismo era a religião predominante no Brasil, os escravos africanos foram obrigados a disfarçar seus Orixás em santos católicos, que cultuavam apenas aparentemente, quando sua real intenção de culto estava direcionada aos seus ancestrais africanos. Conforme estudo consultado ${ }^{14}$ o negro não misturava o santo católico com o orixá africano.

Percebe-se que apesar de terem sido aprisionados, vendidos e transportados para outros continentes, os negros escravizados, não se desfaziam das suas divindades e das suas visões do mundo. É inclusive impossível imaginá-los com postura receptiva e passiva dos padróes culturais e religiosos daqueles que os haviam subjugado. Assim, no interior das irmandades de negros e seus descendentes, emergia um processo de africanização da religião católica, um catolicismo negro ou africano. ${ }^{15}$

A aproximação com as religiões de matriz africana dentro do Museu possibilitou melhor compreensão da cultura religiosa africana, com rompimento de preconceitos, que inegavelmente ainda existe em nossa sociedade, com relação à Umbanda, Candomblé e crença nos Orixás e espíritos ancestrais. A experiência permitiu reflexões sobre a prática do cuidado da enfermagem, uma vez que despertou sensibilidade de compreender e respeitar a fé do outro.

Conhecer as religiões é fundamental no processo de construção de profissionais de saúde capacitados a prestar cuidados que envolvam a integralidade do ser, pois embora o enfermeiro não acredite ou não se identifique com outras religiões que não a sua, ele deve respeitar, estimular a fé e se possível conversar um pouco com o paciente sobre a religião do mesmo. Pessoas convictas em suas religiôes creem na proteção divina e reconhecem a religiosidade como sustento e conforto enquanto paciente e seus familiares, o que ajuda no enfrentamento do adoecimento. ${ }^{16}$

Admitir como verdadeiros outros conhecimentos e suas formas de transmissão, expressões, práticas, representações e técnicas, por meio do patrimônio imaterial, é um avanço que leva a reconhecer a existência passada e presente de diferentes grupos como produtores de cultura, de memória e como agentes de suas histórias. ${ }^{6}$

De tal modo, por meio da visita foi possível repensar valores e condutas, além da capacidade de respeitar e buscar entender, por meio de uma visão ampliada, o contexto cultural e religioso do outro, e revisar práticas em saúde puramente técnicas, para um cuidado que trabalhe a fé junto com a medicina para alcance do bem estar físico e espiritual dos clientes. É imprescindível compreender a dimensão espiritual, para identificar as necessidades espirituais dos pacientes e humanizar o cuidado. ${ }^{17}$

Durante a visita, muitas questões do processo saúde-doença dos escravos africanos foram elencadas, e ficou evidente que apesar do investimento representado por cada escravo, nem todos os proprietários cuidavam adequadamente deles.
Essa é uma questão que merece atenção: a contradição de se cuidar de uma 'coisa' que não é 'sujeito', pois o escravo era visto como mercadoria, apesar de a saúde dos escravos ser precondição na fixação do seu valor, mesmo sem oportunidade a qualquer tratamento de saúde. A questão da saúde dos escravos foi negligenciada e tratada com descaso pelos proprietários de terra e senhores, uma vez que se tratava de mercadoria, numa dinâmica em que não se estabeleciam relações interpessoais, mas sim relações entre sujeito e objeto. ${ }^{18}$

Por meio do seminário extramuros foi perceptível a importância do Museu Senzala, não só como patrimônio histórico, mas porque mantêm viva a história. $\mathrm{O}$ Museu Senzala preserva em sua estrutura vestígios e objetos do cotidiano dos escravos que possibilitaram a construção de nova visão sobre cultura, religiosidade e saúde dos povos africanos por meio das exposições propostas.

Ao assumir papel educativo, o museu instigou rompimento da lógica da aula tradicional, para vivenciar experiência de visualização do passado, por meio de artefatos preservados ao longo do tempo e propor narrativas que problematizaram a trama histórica e conduziram para produção de conhecimento crítico e reflexivo.

A experiência vivida retratou a relevância de novos espaços como metodologia de ensino e aprendizagem, promovendo nos discentes, novas reflexões e pensamentos críticos por meio da observação de fenômenos extramuros da Universidade.

\section{CONCLUSÕES}

O seminário extramuros oportunizou aos mestrandos e docentes, no tocante a ser a primeira cidade a abolir escravos no Brasil, clareza quanto à forma como seres humanos eram tratados e escravizados, e a influência presente hoje, de tradições culturais e religiosas trazidas pelos escravos que não foram perdidas com o tempo.

Foi perceptível que as diversas religiões praticadas no Brasil, têm influência direta dos povos africanos que foram trazidos ao país como meio de trabalho escravo, e que praticavam suas tradiçôes e cultos de forma escondida e silenciada. Religiôes como Um- 
banda e candomblé, muito praticadas no Brasil, tem origem de países africanos, e ainda hoje tem suas tradições mantidas.

É importante destacar que mesmo com o decorrer de tantos anos, o Museu Negro
Liberto preserva o local e objetos aos quais eram utilizados pelos senhores de engenho para aplicação dos castigos e torturas aos escravos, e principalmente quando falamos da preservação da memória dos povos africanos que por aqui passaram. É importante, que este patrimônio se mantenha sempre aberto a estudantes e população em geral, pois só assim, é possível resgatar fatos e marcos reais na história brasileira. -

\section{REFERÊNCIAS}

1. Macedo KDS, Acosta BS, Silva EB, Souza NS, Beck CLC, Silva KKD. Active learning methodologies: possible paths to innovation in health teaching. Esc Anna Nery [Internet]. 2018 [cited 2020 Nov 19]; 22(3):1-9. Available from: https://doi.org/10.1590/21779465-ean-2017-0435

2. Dearnley C, Rhodes C, Roberts P, Williams P, Prenton S. Team based learning in nursing and midwifery higher education; a systematic review of the evidence for change. Nurse Educ Today. [Internet]. 2018 [cited 2020 Nov 22]; 60:75-83. Available from: https://www. sciencedirect.com/science/article/abs/pii/S026069171730223X?via\%3Dihubdoi:10.1016/j.nedt.2017.09.012

3. Brkić Midžić S. A new museum within the Croatian academy of sciences and arts and the first of its kind in Croatia: the Croatian museum of medicine and pharmacy. Acta Med Hist Adriat. [Internet]. 2016 [cited 2020 Nov 23];14(2):201-210. Available from: https:// pubmed.ncbi.nlm.nih.gov/28038483/

4. Sherman A, Cupo L, Mithlo NM. Perspective-taking increases emotionality and empathy but does not reduce harmful biases against American Indians: Converging evidence from the museum and lab. PLoS ONE [Internet]. 2020 [cited 2020 Dec 21]; 15(2): e0228784. Available from: https://doi.org/10.1371/journal. pone. 0228784

5. Melo DB, Carvalho, RCM. Relações entre patrimônio cultural e museus: um referencial teórico para o desenvolvimento. Mosaico [Internet]. 2016 [cited 2020 Dec 17]; 7(10):1-18. Available from: file://C:/Users/Usuario/Downloads/64725-137151-2-PB\%20(1). pdf. doi: http://dx.doi.org/10.12660/rm.v7n10.2016.64725

6. Forti ASD'A. Memória, patrimônio e reparação: políticas culturais no Brasil e o reconhecimento da história da escravidão. Mosaico [Internet]. 2017 [cited 2020 Dec 11]; 8(12):81-102. Available from: file:///C:/Users/Usuario/Downloads/65370-144795-2-PB.pdf. doi: 10.12660/rm.v8n12.2017.65370.

7. Brasil. Governo do Estado do Ceará. Secretaria do Turismo do Ceará. Redenção: conheça a primeira cidade do Brasil a libertar os escravos. 2015. [cited 2020 Dec 14]. Available from: https://www. ceara.gov.br/2015/03/25/redencao-conheca-a-primeira-cidade-do-brasil-a-libertar-os-escravos/

8. Brasil. Prefeitura Municipal de Redenção. Lei $n^{\circ} 1692$ de 3 de Agosto de 2018. Anexo 01: Plano municipal de cultura. 2018 [cited 2020 Nov 23]. Available from: https://www.redencao.ce.gov.br/ arquivos/214/LEIS_1692_2018_0000001.pdf

9. Neitzel AA, Uriate MZ; Franklin, K. O museu de ciências como espaço de provocação dos sentidos. Eccos - Revista Cientifica [Internet]. abr./jun. 2020 [cited 2021 Jan 11]; e 16792(53):1-17. Available from: https://periodicos.uninove.br/eccos/article/view/16792

10. Junior JCV, Pereira JSRC, Braz RMM. Relato de experiência sobre uma aula-passeio ao Museu de arqueologia de Itaipu com crianças com deficiência. Perspectivas em Diálogo: Revista de Educação e Sociedade. [Internet]. jul./dez. 2019 [cited 2021 Jan 11]; 6(13):238-250. Available from: https://periodicos.ufms.br/index. php/persdia/

11. Trouillot M-R. Silenciando el pasado: el poder y la producción de la historia. Vínculos de Historia [Internet]. 2018 [cited 2020 Dec 13]; (7):403-405. Available from: file:///C:/Users/Usuario/Downloads/339-1297-1-PB.pdf.

12. Vassallo SP, Cáceres LSR. Conflitos, verdades e política no Museu da Escravidão e da Liberdade no Rio de Janeiro. Horiz. antropol. [Internet]. 2019 Jan-Abr [cited 2021 Jan 22]; 25(53):47-80. Available from: https://www.scielo.br/scielo.php?script=sci_arttext\&pid=S0104-71832019000100047\&tlng=pt. doi: http://dx. doi.org/10.1590/s0104-71832019000100003.

13. Espírito Santo AS, Silva PC, Araújo CG, Oliveira KAS. Qual é o lugar da macumba? IV seminário formação docente: intersecção entre universidade e escola "Educação Pública em Tempos de Reformas"; 09-11 de Setembro de 2019; Dourados, Mato Grosso do Sul, Brasil. 2019. Available from: file://C:/Users/Usuario/Downloads/5707-13983-1-PB.pdf

14. Silva LCB. "Santo não é Orixá": um estudo do discurso antissincretismo em integrantes de religiões de matriz africana [dissertação]. Recife: Universidade Católica de Pernambuco. Programa de Mestrado em Ciências da Religião; 2010. Available from: http:// tede2.unicap.br:8080/bitstream/tede/884/2/dissertacao_luiz_ claudio.pdf

15. Boschi CC. Confraternidades negras na América portuguesa do Setecentos. Estudos Avançados [Internet]. 2019 [cited 2021 Jan 08]; 33(97):211-233. Available from: https:/www.scielo.br/pdf/ ea/v33n97/0103-4014-ea-33-97-211.pdf. doi: 10.1590/s01034014.2019.3397.012.

16. Espíndula JA, Valle ERM, Bello AA. Religião e espiritualidade: um olhar de profissionais de saúde. Rev. Latino-Am. Enfermagem [Internet]. nov-dez 2010 [cited 2021 Jan 11]; 18(6):1-8. Available from: https://www.scielo.br/pdf/rlae/v18n6/pt_25.pdf

17. Evangelista CB, Lopes MEL, Costa SFG, Abrão FMS, Batista PSS, Oliveira RC. Espiritualidade no cuidar de pacientes em cuidados paliativos: Um estudo com enfermeiros. Esc Anna Nery [Internet]. 2016 [cited 2021 Jan 11];20(1):176-182. Available from: https://www. scielo.br/pdf/ean/v20n1/1414-8145-ean-20-01-0176.pdf

18. Lima PVSF, Oliveira KA, Santos DLR. Aspectos gerais da saúde dos escravos no Brasil: revisão de literatura. Revista Eletrônica Gestão \& Saúde [Internet]. 2016 [cited 2021 Jan 12]; 7(1):471489. Available from: file:///C:/Users/Usuario/Downloads/Dialnet-AspectosGeraisDaSaudeDosEscravosNoBrasil-5555882.pdf 